ENtomophaGa, I5 44$\}, \mathbf{1 9 7 0}, 445$

\title{
ANALYSE BIBLIOGRAPHIQUE
}

F. SCHWERDTFEGER. - Die Waldkrankheiten. Ein Lehrbuch. - P. Parey, Hamburg; 3rd edition, 509 pp., 256 figs., 1970. (DM 68).

The new edition of the well-known textbook on forest pathology keeps alive the authors fundamental point of view that forest pathology and forest protection cannot be fully understood but by consideration of their dependence on the biological and economic unity of the forest. Thus, forest disease means here the sum of damaging influences including abiotic and biotic causes. The new edition has incorporated the recent literature and quoted are only papers that appeared after 1957. 311 pages are devoted to a systematic treatment of forest diseases and their causes, starting with fire, air, weather, and soil, leading to microorganisms, plants and animals, including a special chapter on gradations of pathogenic organisms.

The subsequent general chapters are dealing with the disposition and resistance of the forest, the course of diseases, their economic consequences, and control. The biological control worker finds well balanced reviews of the latest achievement in forest pest control. They comprise the occurrence and utilisation of pathogenic microorganisms as well as the colonisation of entomophagous insects, birds, and bats. The principles of integrated control have been fundamental already to the 1 st edition (194.2) of this book. The separation of biological measures that are intended to act permanently as hygienic measures from therapeutic action of biological control proper may not find general approval. As a whole, however, this book offers a well balanced and thorough review on all important problems of forest pathology sensu latu occurring in Central Europe and up-to-date information on forest pests including their natural enemies and their use. The concise style and clear figures allow the condensation of a wealth of accumulated new facts on only 2-4 pages more than in the 2nd edition of 1957.

$$
\text { J. M. Franz }
$$

\section{J. BRIEJER. - Silberne Schleier. Gefahren chemischer Bekämpfungsmittel. -} Biederstein-Verlag, Nünchen, $27 \iota_{1}$ pp., 1970.

The author, a well known expert for pesticides and the former director of the Dutch Plant Protection Service, offers a impressive description of the hidden dangers of chemical pest control. Although his style is simple and destined for laymen, the sincere intention is felt on each page to take away the silver veil hiding the cruel facts of side-effects of the use of chemicals to control pest organisms. Resistance of insects against insecticides, and danger's to the health of mankind, particularly of children, are two of his main topics. Proceeding through the door opened by the alarming book by Rachel Carson, this one concerns us in Europe still more as it is written by an expert for European conditions. The translation of the original Dutch version should widen the impact of a book that may well develop the attitude of both, the public and the Government authorities, in a direction which prove to be quite open for biological and other non-conventional methods of pest will control.

J. M. Franz. 